\title{
Cervical rib and thoracic outlet syndrome
}

\begin{abstract}
The cervical rib is an extra rib that develops as a result of elongation of the costal element of the transverse mass of the $\mathrm{C} 7$ vertebra. Its incidence ranges from less than 0.5 to $2.5 \%$, with some gender and laterality predilections, in different populations. It is rarely symptomatic. When large, it can cause various vascular and neurological symptoms. Thoracic outlet syndrome (TOS) is a group of manifestations that result from compression of one or more of the neurovascular structures in the thoracic outlet. The causes of TOS include musculoskeletal variations or anomalies, fibrous bands, tumors and post-traumatic conditions. Clinically, three forms of the TOS are identified: arterial, venous and neurogenic. Surgical options for decompression of the TOS include the transaxillary, the supraclavicular and the posterior subscapular approaches.
\end{abstract}

Keywords: cervical rib, thoracic outlet syndrome, TOS, cuses, surgical approaches
Volume 2 Issue 5 - 2016

\author{
Heshmat SW Haroun \\ Faculty of Medicine, Cairo University, Egypt
}

Correspondence: Heshmat SW Haroun, Professor of Anatomy and Embryology, Faculty of Medicine, Cairo University, Egypt, Email heshmatsabet@hotmail.com

Received: April |I, 2016 | Published: June 07, 2016

\section{Introduction}

A cervical rib is a supernumerary rib that occasionally projects from the lateral mass of the 7th cervical vertebra. Clinically, it can cause obscure nervous or vascular symptoms, and it is difficult to diagnose. Studies have shown the prevalence of cervical ribs to lie between $0.03 \%$ on radiographs and 3\% in postmortem investigations, depending on the sex and race of the population studied. The term thoracic outlet syndrome (TOS) refers to a heterogeneous group of disorders that compress one or more of the neurovascular elements within the thoracic outlet (superior aperture of the thoracic cavity) on their way to the axilla. Cervical ribs are congenital variants that are known to cause TOS or brachial plexopathy in up to $10 \%$ of the affected individuals. In symptomatic cervical rib, surgical rib resection may be adopted.

\section{Morphological and developmental aspects of cervical rib}

The presence of a foramen transversarium in each of the lateral masses is a characteristic feature of all cervical vertebrae. It allows the passage of the vertebral artery; an important artery supplying the brain and spinal cord. This foramen is bounded by bony elements: the anterior and posterior roots, the anterior and posterior tubercles, and the costotrasverse bar. Developmentally, the posterior root represents the true the transverse process while the remaining bony parts represent the costal element that when elongated it results in a supernumerary rib. ${ }^{1}$

Thoracic vertebrae typically bear facets on the sides of their bodies and on the transverse processes for articulation with the heads and tubercles of the ribs, respectively. A complete foramen in the left transverse process of the first thoracic vertebra has been discovered as a very rare anatomical variation, it was present near the root of the transverse process in alignment with the foramina transversaria of the cervical vertebrae of the same side. ${ }^{2}$ There is a single report of an adult possessing a phalanx-like bone in the cervical region, it lay posterior to the spinous process of the $\mathrm{C} 5$ vertebra, and it was attached to the left lamina of the $\mathrm{C} 5$ vertebra. ${ }^{3}$ Growth differentiation factor 11 (GDF11) is one of the significant genes that is considered to control skeletal formation. It was observed to induce formation of extra rib in mice as a result of transformation of the $\mathrm{C} 7$ vertebra into a thoracic vertebra. $^{4}$

The prevalence of cervical ribs in the human population has been a source of uncertainty due to the difficulty in detecting this often subtle congenital variation. The incidence of cervical rib is mentioned, in one reprot, to be less than $1 \%$ of the population. ${ }^{5}$ The prevalence of the transverse process elongation and cervical ribs was investigated in a Saudi population showing that cervical ribs were present in $3.4 \%$; a female to male ratio was 2.01 to 1 ; they were bilateral in $41 \%$ of affected individuals, and elongated transverse processes were present in $23 \% .{ }^{6}$ On MRI examinations, cervical ribs were identified on $1.2 \%$ scans, being lower than on CT scans $(2 \%){ }^{7}$ In Americans, cervical ribs were found in $2.0 \%$ of the population; of them $40.3 \%$ had bilateral ribs. The prevalence of cervical ribs in women was assessed to be twice that in men, and African Americans constituted $70.1 \%$ of patients with cervical ribs, whereas whites were $26.9 \%{ }^{8}$ In a London population of mixed sex and ethnicity, the incidence of cervical rib was $0.74 \%$ with a higher rate in females compared with males ( 1.09 and $0.42 \%$, respectively). Of 10 individuals with a cervical rib, five were on the left side, three were on the right side and two were bilateral. The presence of elongated $\mathrm{C} 7$ transverse processes (transverse apophysomegaly) was noted in $2.21 \%$ of population. ${ }^{9}$

In gestational ages ranging from less than 18 weeks to 42 weeks, calculated from the LMP, a separate costal element of the C7 vertebra, the possible precursor of a cervical rib, could be observed in $63 \%$ of fetuses with males outnumbering females (403:311). Of the cases with separate costal elements, $73 \%$ were bilateral and of the unilateral group $60 \%$ were on the right and $40 \%$ on the left side. Nonsignificant differences were correlated to the gestational ages with disappearance of the separate costal element after birth. ${ }^{10}$ The overall prevalence of cervical ribs was found to be higher in stillborn fetuses than in live born infants and they were strongly associated with fetal aneuploidy. ${ }^{11}$ In a study on adult dry and clean C7 vertebrae of Egyptians, the mean length values of the anterior root, the costotransverse bar, and the whole costal element were assessed to be $11.3 \pm 4.06 \mathrm{~mm}$ (on right side) and $13.9 \pm 4.97$ (on left side), $12.8 \pm 3.20 \mathrm{~mm}$ (on right side) and $11.0 \pm 2.79$ (on left side), and $24.6 \pm 4.95 \mathrm{~mm}$ (on right side) and $25.1 \pm 4.55 \mathrm{~mm}$ (on left side), respectively. ${ }^{12}$ 
Anomalies of the bilaterally dissected thoraco-cervico-axillary regions, of 40 aborted human fetuses, were discovered in $60 \%$ of the dissections. The scalene hiatus, between the scaleni anterior and medius muscles, had an oval shape in $6.3 \%$. Fibromuscular bands were found in $15 \%$ of the fetuses while hypertrophied scalenus anterior muscle was seen in $12.5 \%$ of the dissections. In $28.7 \%$ of the cervical dissections, hypertrophy of the $\mathrm{C} 7$ transverse process was noted, being bilateral in seven cases. In one case, a "C-shaped" clavicle anomaly was observed. Absent internal thoracic artery was also noted in one case. ${ }^{13}$

\section{Thoracic outlet syndrome (TOS) and its clinical types}

Thoracic outlet syndrome (TOS) is a controversial clinical entity in medicine that is defined as a set of symptoms induced by the compression of the brachial plexus and subclavian vessels on their way from the thoracic outlet to the axilla. The term TOS refers to a group of disorders that have, in common, the entity of compression of one or more neurovascular elements at some point within the thoracic outlet. Most of these disorders have all of the expected parameters of a syndrome: a recognized group of clinical features, an anatomical derangement accounting for these features, and a diagnostic method for identification of this anatomical derangement; hence their recognition and management are relatively straight forward..$^{14}$

Anomalies in musculoskeletal structures that may be responsible for the TOS include prolonged transverse process of the $\mathrm{C} 7$ vertebra, cervical rib, anomalous first rib, and clavicle fractures. Cervical ribs may cause TOS in adults, but symptoms are poorly described in children. In a study on a group of children with cervical ribs, $88.8 \%$ were asymptomatic. The most common symptoms, in this group, were neck mass and pain. Useful diagnostic tools, in these conditions, were cervical spine and chest radiographs, considering the differential diagnosis of a supraclavicular mass including cervical ribs. ${ }^{15}$ An asymptomatic cervical rib presenting as a hard neck lump was also discovered in a 56year-old woman. ${ }^{16}$

Skeletal anomalies are recognized as potential causes of thoracic outlet syndrome (TOS).${ }^{17-20}$ A retrospective clinical and imaging study was conducted, on 400 patients operated upon for the TOS, to identify the prevalence of bone anomalies associated with different clinical types of the syndrome. Of the total number of patients, only $29 \%$ exhibited a bone anomaly in the form of cervical ribs (69\%), clavicular anomalies $(22 \%)$ and isolated first rib aberrations (9\%). Of the bone anomalies $78 \%$ were congenital while $22 \%$ were post-traumatic. The bone anomalies were predominantly found in females $(76 \%)$ with an average age of 36 years. The distribution of neurogenic, arterial and venous types of the TOS, with bone anomalies, was $63 \%, 33 \%$ and $4 \%$, respectively. ${ }^{21}$ Bifid rib is usually asymptomatic anomaly but sometimes is associated with other pathological conditions when there is downward extension of the cervical or first rib to articulate with the upper branch of the bifid first or second rib, respectively. ${ }^{22,23}$

Based on the underlying structure(s) compressed, the TOS has traditionally been divided into vascular and neurogenic types, of which neurogenic TOS (nTOS) is commoner (95\%) and typically presents with compression of the brachial plexus; mostly the lower trunk. Vascular TOS (vTOS) primarily involves compression of the subclavian artery or vein, or it is sometimes secondary to thrombus formation in the venous vasculature. Anatomical anomalies in the thoracic outlet has the potential to predispose to any of the types of the TOS like variable insertions of scalenus anterior, scalenus minimus or pectoralis mino muscle, cervical rib, fibrous and muscular bands, and atypical course of neurovascular structures of the outlet. ${ }^{24}$

\section{Vascular type of TOS (vTOS)}

Cervical ribs are rarely symptomatic. ${ }^{25}$ Stroke is an exceedingly rare presentation of arterial thoracic outlet syndrome (aTOS). Subclavian arterial compression is usually due to a cervical rib, and is rarely associated with thromboembolic or ischaemic stroke. The mechanism of cerebral embolisation associated with the thoracic outlet syndrome is poorly understood, but may be due to retrograde propagation of thrombus or transient retrograde flow within the subclavian artery exacerbated by arm abduction. ${ }^{26-29}$ Cerebral ischemia or infarct due to cervical rib is extremely rare and these patients usuall have a history of upper limb symptoms before the initial presentation with a stroke. ${ }^{30}$ Subclavian arterial thrombosis and both cerebellar and cerebral infarctions secondary to retrograde thromboembolisation were reported in a middle-aged male with a right cervical rib. The cervical and first ribs were surgically removed to prevent further events. ${ }^{31}$ An unusual case of thrombosis of left subclavian artery in a female patient with bilateral cervical rib, longer on the left side, was described, embolectomy was performed and the patient was planned for rib excision. ${ }^{32}$

Cervical ribs causing clinical symptoms are large, frequently fused with the first rib, and they can result in aneurysmal formation or thrombosis. In such cases, both the cervical and first ribs have to be excised to relieve arterial compression, usually through a transaxillary approach unless in patients with aneurysms, needing arterial reconstruction where a supraclavicular approach is adopted. ${ }^{33}$ There is a report of three patients who had arterial thoracic outlet syndrome associated with a cervical rib that was fused to the second rib in the absence of the first rib. These patients underwent transaxillary cervical and second rib resections together with anterior scalenectomy; complete resolution of the symptoms had occurred. ${ }^{34}$ Stenosis of the internal jugular vein is also noted in some cases of thoracic outlet syndrome. ${ }^{35}$ It is postulated that aggregated costochondral calcifications may predispose to osteophyte formation and stressinduced occult first rib fractures, and that neighbouring soft tissue inflammation, fibrosis, and anatomical disruption may contribute to subclavian vein compression (venous TOS) ${ }^{36}$ Regrown, remaining or residual cervical or first rib is the cause of recurrent TOS. ${ }^{37-39}$

Some authors described a case of a young woman with pain in the left forearm, accompanied by intermittent claudication, weight loss, myalgias, ischemia of the fingers, no radial pulse, and no measurable blood pressure in the left arm. The case was initially diagnosed as "Takayasu arteritis". However, chest radiography showed accessory cervical ribs while Doppler ultrasonography and angiography revealed bilateral compression of the subclavian artery. ${ }^{40}$ Embolism of the arm and finger arteries can occur with a cervical rib, mild or moderate symptoms could be relieved through a conservative treatment, while severe cases may necessitate surgical resection of the cervical and first ribs. $^{41}$

\section{Neurogenic type of TOS (nTOS)}

The most common clinical presentation of the TOS arises from compression of the lower trunk of the brachial plexus. In a study on embalmed cadavers, a fibrous band consistent with Roos' type 3 was identified in 41 percent of cadavers and it had dimensions of $3.45 \times 0.27 \mathrm{~cm}$. It lay anterior to the $\mathrm{T} 1 \mathrm{ventral}$ primary ramus, creating a tunnel through which this nerve root must ascend before joining the 
C8 nerve root to form the lower trunk of the brachial plexus. It was believed that such a tunnel could compress the $\mathrm{T} 1$ nerve root against the first rib, potentially predisposing in susceptible individuals to thoracic outlet syndrome. ${ }^{42}$ This fibrouse band, sometimes called the "first thoracic rib ligament or intracostal ligament", can cause preclavicular entrapment of the T1 ventral primary ramus leading to radiculopathy, nTOS, or both, the so called "double crush" phenomenon. This ligament was demonstrated in $81 \%$ of embalmed cadavers: $52 \%$ bilateral and $29 \%$ unilateral. It was trapezoidal in shape, being wider anteriorly. Its average length was $31.0 \mathrm{~mm}$, anterior width was $7.1 \mathrm{~mm}$, midsubstance width $3.6 \mathrm{~mm}$, and posterior width $3.5 \mathrm{~mm}$. Its mean thickness was $0.5 \mathrm{~mm}$, and the maximal opening through which the $\mathrm{T} 1$ nerve passed between the first rib and the ligament was $6.3 \mathrm{~mm}^{43}$

Symptomatic cervical ribs should not be considered as a pathology peculiar to the adult population but although uncommon, they may present in children with neurological sequelae that may necessitate surgical intervention. ${ }^{44,45}$ The causes of neonatal brachial plexus palsy include obstetrical palsy, familial congenital palsy, maternal uterine malformation, congenital varicella syndrome, osteomyelitis involving the head of the humerus or cervical vertebral bodies, exostosis of the first rib, tumors and hemangioma in the region of the brachial plexus, and intrauterine maladaptation. ${ }^{46}$ Congenital brachial plexus palsy (CBPP) usually occurs as a birth injury but this is not always the case. Cervical ribs are reported to increase the risk of CBPP in association with birth injury. ${ }^{46-48}$

A true neurogenic thoracic outlet syndrome associated with a cervical rib is considered extremely rare. Five females of "true nTOS" associated with radiographically confirmed cervicl ribs and of average age of 34.8years described their pain as intense and debilitating before surgical treatment. They were operated on via a supraclavicular approach and the cervical ribs were resected. Two years postoperatively, all patients felt improvement and they were able to resume their daily life activities. ${ }^{49}$

Atrophy of the intrinsic muscles of the hand is considered to be a typical feature of the true form of the "nTOS". The classical type of this entity has been described to consist of a cervical rib or a prolonged transverse process of the $\mathrm{C} 7$ vertebra, completed with a fibrous band attached to the first thoracic rib, and resulting in atrophy of the intrinsic muscles of the hand. Based on this observation, the "nTOS" is currently classified in clinical practice into "disputed" and "true" neurologic subgroups. In all cases of the "true nTOS" with atrophy of the intrinsic muscles of the hand, the lateral thenar muscles are affected first. ${ }^{50}$ The majority of patients suffering from a post-traumatic TOS present with a neurogenic type of the syndrome. ${ }^{51}$ It has been emphasized that intrinsic hand muscle and lateral thenar muscle atrophy and weakness, as well as medial hand and forearm numbness are all suggestive of lower trunk involvement in "nTOS", and this condition is very rare to occur in the pediatric population. ${ }^{52}$

Cervical rib or elongated costal element of the $\mathrm{C} 7$ vertebra and sacralization of a lumbar vertebra are associated with neurological, vascular, and obstetrical problems. An association between these three morphological variations is reported with a suggestion that clinicians could use the incidence of one of them to predict the presence of the others. However, another study has presumed that sacralization is not a predicate for either cervical rib or elongated transverse process of the $\mathrm{C} 7$ vertebra. ${ }^{53}$ Furthermore, isolated cervical rib fracture and cervical rib pseudoarthrosis are reported to be extremely rare causes of TOS..$^{54-56}$

The scalenus minimus muscle strengthens the suprapleural membrane (Sibson's fascia) and it extends from the anterior tubercle of the transverse process of the $\mathrm{C} 7$ vertebra to the inner border of the first rib and cupula of the pleura. A large scalenus minimus muscle was detected on the right side of a dissected white old male cadaver in Saudi Arabia. This case was considered as noteworthy because of its great dimension and relation to the brachial plexus. ${ }^{57}$

Actions of the scalene muscles include ventral and lateral flexion of the cervical spine as well as elevation of the first and second ribs. Rotation of the cervical column by these muscles remains a subject of debate. Experimental models of the scalene muscles supported the accepted main actions of the muscles and succeeded to produce ipsilateral rotation of the cervical spine. An assumption was raised that a knowldge of the cervical rotational properties of the scaleni helps in the clinical diagnosis, management, and treatment of cervical pain conditions as well as thoracic outlet syndrome. ${ }^{58}$

Patients with "nTOS" may have signs and symptoms of concomitant arterial compromise without thrombosis or aneurysm. ${ }^{59,60} \mathrm{~A}$ potential relationship has been elucidated between carpal tunnel syndrome (CTS) and TOS. A great number of subjects with CTS presented with history of neck and shoulder pain suggestive of TOS. ${ }^{61}$

\section{Histopathological changes in "nTOS"}

Histopathological studies, on human cadavers, had demonstrated the structural changes induced by cervical rib compression in the lower trunk of the brachial plexus. These changes included epi- and perineurial fibrosis leading to thickening with intersecting fibrous bands, vascular hyalinization, focal mucinous degeneration of the nerve fasciculi, and frequent intraneural collagenous nodules. None of the control cadavers had shown such histological findings. ${ }^{62}$

\section{Diagnostic aids and surgical approaches for TOS}

Helical computed tomography provides a three-dimensional view of the thoracic outlet, and is valuable for the detection of anatomical variations there. A common diagnostic technique for "vTOS" is duplex imaging, which has generally replaced the more invasive angiographic techniques. In cases of suspected "nTOS", electrophysiological nerve studies offer guidance in patients likely to benefit from surgical decompression of TOS. In children, musculoskeletal sonography may be a reliable method for diagnosis of cervical ribs without the need for ionizing radiation. ${ }^{63}$

Vascular and neurogenic compression induced by cervical ribs should be promptly diagnosed and treated in order to avoid further complications, including cerebrovascular ischemic events. Different surgical approaches are available for the treatment of TOS. ${ }^{64}$ Early surgical intervention is recommended in patients with upper limb ischemia and anatomical abnormalities in a thoracic outlet. A middleaged male with progressive ischemia of the right upper limb due to compression of the subclavian artery by an accessory cervical rib had undergone cervical rib resection together with a subclavio-brachial venous bypass graft. Recovery of the limb ischemia and healing of the finger ulcerations were permanently observed. ${ }^{65}$

Recurrent supratentorial and infratentorial stroke in the same patient is very rare particularly when it occurs in the young. Cervical rib can induce anterograde or retrograde thromboembolic phenomenon leading to ischemic stroke. Such a case could be managed through anticoagulant and antiplatelet therapy followed by excision of the cervical rib. ${ }^{66}$ In a group of paients with "vTOS", the 
causes of arterial compression were identified to include cervical rib in $74.1 \%$, abnormal first thoracic rib in $11.1 \%$, soft tissue anomalies in $7.4 \%$, and hypertrophic callus of healed clavicle fracture in $7.4 \%$. In all cases, a combined supraclavicular and infraclavicular approach was performed. Decompression was achieved through cervical rib excision in $48.1 \%$, combined cervical and first rib excision in $26 \%$, and first rib excision in $22.2 \%$ of patients. Associated vascular procedures included resection and replacement of the subclavian artery, subclavian-axillary or axillary-brachial bypass, or brachial embolectomies. ${ }^{67}$

The transaxillary approach is one of the surgical approaches described for the treatment of "nTOS". It lies along a natural corridor, is non-muscle splitting, allows definitive treatment of both bony and soft-tissue variations in thoracic oulet, produces minimal complications, and preservs the anatomical boundaries. However, a persistent cervical rib requires an additional ventral cervical approach. ${ }^{68}$ It is also claimed that the transaxillary approach is considered as the golden management standard because it provides wide exposure and good cosmesis in patients with TOS. ${ }^{69}$

Endoscopic computerized instrumentation in transaxillary first rib resection (FRR) decreases the risk of neurovascular or pleural damage, promotes complete decompression, and consequently provides a safe alternative to standard method of FRR..$^{70,71}$

A supraclavicular incision at the base of the neck is favored by some surgeons for decompression of the TOS. This approach has been found to provide ample access to the brachial plexus, the subclavian vessels, and the cervical and first ribs. This procedure not only relieves pain but also is cosmetically acceptable..$^{72}$ Adolescents undergoing supraclavicular decompression of "nTOS" are reported to have more favorable preoperative characteristics and more enhanced 3-month and 6-month functional outcomes than adults. ${ }^{73}$ Supraclavicular approach for FRR remains an essential step in the management of the TOS particularly when there are no bony abnormalities, it has a minimal morbidity and an excellent outcome. ${ }^{74}$

First rib resection and scalenectomy (FRRS) has been shown to improve short-term quality of life (QOL) in the treatment of the "nTOS". ${ }^{75}$ Venous bilateral TOS patients are more oftenly younger, competitive athletes, and they require close postoperative monitoring for recurrent stenosis and thrombosis. ${ }^{76}$ In a series of patients who underwent FRR for all of the three forms of the TOS: neurogenic, venous, and arterial, during a period of 10years, excellent outcomes were obtained. An increasing role for surgical intervention in children was reported. ${ }^{77}$

A posterior subscapular approach to the brachial plexus is commonly indicated in patients with the "nTOS" especially when associated with a large $\mathrm{C} 7$ transverse process or cervical rib, paraspinal tumors, or lacerations of the spinal nerves close to the spine. This approach is also preferred in patients with previous anterior neck operations and/or morbid obesity. ${ }^{78}$ In a case of a 37year-old woman critical upper limb ischemia caused by a cervical rib was discovered, vascular bypass was performed with cinical failure, and after a 6month therapy with sildenafil, successful revascularization of the arm was observed and amputation was avoided. ${ }^{79}$

\section{Acknowledgements}

None.

\section{Conflict of interest}

Author declares that there is no conflict of interest.

\section{References}

1. Warwick R, Williams PL. Gray’s Anatomy. BJS. 1973;98(3):218.

2. Gupta M, Agarwal S, Paul S. An unusual foramen in the transverse process of first thoracic vertebra. Anat Sci Int. 2013;88(2):106-108

3. Nakano Y, Aizawa M, Kako Y, et al. A neonate with an anomalous bone attached to the cervical spine. Spine J. 2013;13(7):5-7.

4. Li Z, Kawasumi M, Zhao B, et al. Transgenic over-expression of growth differentiation factor 11 propeptide in skeleton results in transformation of the seventh cervical vertebra into a thoracic vertebra. Mol Reprod Dev. 2010;77(11):990-997.

5. Wise R. Seventh cervical rib associated with subclavian artery occlusion and multiple infarcts: case report. JNeurosci Nurs. 2008;40(3):169-172.

6. Bokhari RF, Al Sayyad MJ, Baeesa SS. Prevalence of cervical ribs and elongated transverse processes in Saudi Arabia. Saudi Med J. 2012;33(1):66-69.

7. Walden MJ, Adin ME, Visagan R, et al. Cervical ribs: identification on MRI and clinical relevance. Clin Imaging. 2013;37(5):938-941.

8. Viertel VG, Intrapiromkul J, Maluf $\mathrm{F}$, et al. Cervical ribs: a common variant overlooked in CT imaging. Am $J$ Neuroradiol. 2012;33(11):2191-2194

9. Brewin J, Hill M, Ellis H. The prevalence of cervical ribs in a London population. Clin Anat. 2009;22(3):331-336.

10. Mc Nally E, Sandin B, Wilkins RA. The ossification of the costal element of the seventh cervical vertebra with particular reference to cervical ribs. J Anat. 1990;170:125-129.

11. Furtado LV, Thaker HM, Erickson LK, et al. Cervical ribs are more prevalent in stillborn fetuses than in live-born infants and are strongly associated with fetal aneuploidy. Pediatr Dev Pathol. 2011;14(6):431-437.

12. Heshmat SWH. Statistical study of the length of the costal element of the seventh cervical vertebra. Med J Cairo Univ. 1991;59(4):65-68.

13. Fodor M, Fodor L, Ciuce C. Anomalies of thoracic outlet in human fetuses: anatomical study. Ann Vasc Surg. 2011;25(7):961-968.

14. Ferrante MA. The thoracic outlet syndromes. Muscle Nerve. 2012;45(6):780-795.

15. Chan KH, Gitomer SA, Perkins JN, et al. Clinical presentation of cervical ribs in the pediatric population. J Pediatr. 2013;162(3):635-636.

16. Leong SC, Karkos PD. A "hard" neck lump. Singapore Med J. 2009;50(4):141-142.

17. Prescher A, Schuster D. Anatomy of the lateral cervical region with emphasis on thoracic outlet syndrome. Handchir Mikrochir Plast Chir. 2006;38(1):6-13.

18. Khatib N, Boulet J. Thoracic outlet syndrome: a congenital case manifesting in middle age. CMAJ. 2015;187(3):206.

19. De Martino RR, Stone DH, Beck AW, et al. Thoracic outlet syndrome associated with a large cervical rib. Angiol Sosud Khir. 2009;43(4):393-394.

20. Huang JH, Zager EL. Thoracic outlet syndrome. Neurosurgery. 2004;55(4):897-902.

21. Weber AE, Criado E. Relevance of bone anomalies in patients with thoracic outlet syndrome. Ann Vasc Surg. 2014;28(4):924-932.

22. Kaneko H, Kitoh H, Mabuchi A, et al. Isolated bifid rib: clinical and radiological findings in children. Pediatr Int. 2012;54(6):820-823.

23. Cağli K, Ozçakar L, Beyazit M, et al. Thoracic outlet syndrome in an adolescent with bilateral bifid ribs. Clin Anat. 2006;19(6):558-560. 
24. Klaassen Z, Sorenson E, Tubbs RS, et al. Thoracic outlet syndrome: a neurological and vascular disorder. Clin Anat. 2014;27(5):724-732.

25. Becker MH, Lassner F. The asymptomatic thoracic outlet compression syndrome. Handchir Mikrochir Plast Chir. 2006;38(1):51-55.

26. Palmer OP, Weaver FA. Bilateral cervical ribs causing cerebellar stroke and arterial thoracic outlet syndrome: a case report and review of the literature. Ann Vasc Surg. 2015;29(4):840.

27. Nilesh GK, Vimal KP, Zafar N, et al. Retrograde thromboembolic vertebra basilar artery infarct due to right cervical rib. Neurology India. 2014;62(4):479-480.

28. Ella MM, Jason C, Greg F, et al. Thromboembolic stroke associated with thoracic outlet syndrome. J Clin Neurosci. 2014;21(5):886-889.

29. White PW, Fox CJ, Feuerstein IM. Cervical rib causing arterial thoracic outlet syndrome. J Am Coll Surg. 2009;209(1):148-149.

30. Sharma S, Kumar S, Joseph L, et al. Cervical rib with stroke as the initial presentation. Neurol India. 2010;58(4):645-647.

31. Jusufovic M, Sandset EC, Popperud TH, et al. An unusual case of the syndrome of cervical rib with subclavian artery thrombosis and cerebellar and cerebral infarctions. BMC Neurol. 2012;12:48.

32. Sharma P, Rasheed I, Ansari MA, et al. Cervical rib causing thrombosis of subclavian artery. JNMA J Nepal Med Assoc. 2010;49(178):161-163.

33. Chang KZ, Likes K, Davis K, et al. The significance of cervical ribs in thoracic outlet syndrome. J Vasc Surg. 2013;57(3):771-775.

34. Hines K, Graf E, Liu D, et al. The rare case of cervical rib fusion to the second rib. Ann Vasc Surg. 2014;28(3):742.

35. Ahn SS, Miller TJ, Chen SW, et al. Internal jugular vein stenosis is common in patients presenting with neurogenic thoracic outlet syndrome. Ann Vasc Surg. 2014;28(4):946-950.

36. Sheng GG, Duwayri YM, Emery VB, et al. Costochondral calcification, osteophytic degeneration, and occult first rib fractures in patients with venous thoracic outlet syndrome. J Vasc Surg. 2012;55(5):1363-1369.

37. Gelabert HA, Jabori S, Barleben A, et al. Regrown first rib in patients with recurrent thoracic outlet syndrome. Ann Vasc Surg. 2014;28(4):933-938.

38. Likes K, Rochlin DH, Salditch Q, et al. Diagnostic accuracy of physician and self-referred patients for thoracic outlet syndrome are excellent. Ann Vasc Surg. 2014;28(5):1100-1105.

39. Likes K, Dapash T, Rochlin DH, et al. Remaining or residual first ribs are the cause of recurrent thoracic outlet syndrome. Ann Vasc Surg. 2014;28(4):939-945.

40. dos Reis NET, Pucinelli ML, Silva de SAW, et al. Thoracic outlet syndrome (TOS) mimicking Takayasu's arteritis--case report. Acta Reumatol Port. 2009;34(1):96-101.

41. Henes J, Oberländer Y, Tepe G, et al. Unusual reason for unilateral (corrected) Raynaud's phenomenon with intensification when the arms are elevated. Dtsch Med Wochenschr. 2009;134:F3.

42. Spears J, Kim DC, Saba SC, et al. Anatomical relationship of Roos' type 3 band and the T1 nerve root. Plast Reconstr Surg. 2011;128(6):1257-1262.

43. Matullo KS, Duncan IC, Richmond J, et al. Characterization of a first thoracic rib ligament: anatomy and possible clinical relevance. Spine. 2010;35(23):2030-2034.

44. Tubbs RS, Muhleman M, Miller J, et al. Cervical ribs with neurological sequelae in children: a case series. Childs Nerv Syst. 2012;28(4):605-608.

45. Lebhar J, Marleix S, Fraisse B, et al. Thoracic outlet syndrome in a child: a rare pediatric diagnosis. Arch Pediatr. 2013;20(1):30-32.
46. Alfonso DT. Causes of neonatal brachial plexus palsy. Bull NYU Hosp Jt Dis. 2011;69(1):11-16.

47. Desurkar A, Mills K, Pitt M, et al. Congenital lower brachial plexus palsy due to cervical ribs. Dev Med Child Neurol. 2011;53(2):188-190.

48. Tzou CH, Paternostro ST, Frey M, et al. Birth brachial plexus palsy caused by cervical rib. J Plast Reconstr Aesthet Surg. 2014;67(7):1004-1005.

49. Millan G, Casal D, Sagaribay A, et al. Neurogenic thoracic outlet syndrome associated with cervical rib. Acta Reumatol Port. 2013;38(2):98-103.

50. Hug U, Jung FJ, Guggenheim M, et al. True Neurologic Thoracic Outlet Syndrome- Anatomie und elektrophysiologischer Langzeitverlauf bei lateraler Thenaratrophie. Handchir Mikrochir Plast Chir. 2006;38(1):42-45.

51. Dubuisson A, Lamotte C, Foidart DM, et al. Post-traumatic thoracic outlet syndrome. Acta Neurochir. 2012;154(3):517-526.

52. Rivera VA, Peguero L, Colon E, et al. Fibrotendinous band causing neurogenic Thoracic Outlet Syndrome in adolescent with bilateral cervical ribs. J Pediatr Rehabil Med. 2011;4(2):149-154.

53. Tague RG. Sacralization is not associated with elongated cervical costal process and cervical rib. Clin Anat. 2011;24(2):209-217.

54. Dar RA, Wani SH, Mushtaque M. Isolated cervical rib fracture: a rare etiology of thoracic outlet syndrome. Case Rep Surg. 2011;2011:163792.

55. Kamath GS, Borkar S, Chauhan A, et al. Isolated cervical rib fracture. Ann Thorac Surg. 2010;89(6):41-42.

56. Martins RS, Siqueira MG. Cervical rib fracture: an unusual etiology of thoracic outlet syndrome in a child. Pediatr Neurosurg. 2007;43(4):293-296.

57. Sanli EC, Aktekin M, Kurtoglu Z. A case of large scalenus minimus muscle. Neurosciences. 2007;12(4):336-337.

58. Olinger AB, Homier P. Functional anatomy of human scalene musculature: rotation of the cervical spine. J Manipulative Physiol Ther. 2010;33(8):594-602.

59. Likes K, Rochlin DH, Call D, et al. Coexistence of arterial compression in patients with neurogenic thoracic outlet syndrome. JAMA Surg. 2014;149(12):1240-1243.

60. Ried M, Diez C, Wiebe K, et al. Progredient neurogenic and vascular thoracic outlet syndrome due to bilateral cervical ribs. Ann Thorac Surg. 2010;89(3):988.

61. Vaught MS, Brismée JM, Dedrick GS, et al. Association of disturbances in the thoracic outlet in subjects with carpal tunnel syndrome: a case control study. J Hand Ther. 2011;24(1):44-51.

62. Tubbs RS, Louis RG, Wartmann CT, et al. Histopathological basis for neurogenic thoracic outlet syndrome. Laboratory investigation. $J$ Neurosurg Spine. 2008;8(4):347-351.

63. Mangrulkar VH, Cohen HL, Dougherty D. Sonography for diagnosis of cervical ribs in children. J Ultrasound Med. 2008;27(7):1083-1086.

64. Dragu A, Lang W, Unglaub F, et al. Thoracic outlet syndrome: differential diagnosis and surgical therapeutic options. Chirurg. 2009;80(1):65-76.

65. Dzieciuchowicz $Ł$, Włodarczyk W, Oszkinis G. Critical upper limb ischemia caused by initially undiagnosed thoracic outlet syndrome-case report. Pol Przegl Chir. 2012;84(3):158-162.

66. Kataria R, Sharma A, Srivastava T, et al. Cervical rib, a rare cause of recurrent stroke in the young: case report. Neurologist. 2012;18(5):321-323.

67. Davidović LB, Koncar IB, Pejkić SD, et al. Arterial complications of thoracic outlet syndrome. Am Surg. 2009;75(3):235-239. 
68. Krishnan KG, Pinzer T, Schackert G. The transaxillary approach in the treatment of thoracic outlet syndrome: a neurosurgical appraisal. Zentralbl Neurochir. 2005;66(4):180-189.

69. Lattoo MR, Dar AM, Wani ML, et al. Outcome of trans-axillary approach for surgical decompression of thoracic outlet: a retrospective study in a tertiary care hospital. Oman Med J. 2014;29(3):214-216.

70. Martinez BD, Wiegand CS, Evans P, et al. Computer-assisted instrumentation during endoscopic transaxillary first rib resection for thoracic outlet syndrome: a safe alternate approach. Vascular. 2005;13(6):327-335.

71. Candia de la RRF, Pérez RA, Candia GR, et al. Endoscopic transaxillary first rib resection for thoracic outlet syndrome: a safe surgical option. Cir Cir. 2010;78(1):53-59.

72. Weigel G, Schmidt M, Gradl B, et al. TOS-surgery via a single supraclavicular incision. Acta Neurochir Suppl. 2007;100:141-143.

73. Caputo FJ, Wittenberg AM, Vemuri C, et al. Supraclavicular decompression for neurogenic thoracic outlet syndrome in adolescent and adult populations. J Vasc Surg. 2013;57(1):149-157.
74. Yaseen Z, Baram A. Neurogenic thoracic outlet syndrome treatment by the supraclavicular approach. Asian Cardiovasc Thorac Ann. 2014;22(2):193-196.

75. Rochlin DH, Gilson MM, Likes KC, et al. Quality-of-life scores in neurogenic thoracic outlet syndrome patients undergoing first rib resection and scalenectomy. J Vasc Surg. 2013;57(2):436-443.

76. Rochlin DH, Orlando MS, Likes $\mathrm{KC}$, et al. Bilateral first rib resection and scalenectomy is effective for treatment of thoracic outlet syndrome. J Vasc Surg. 2014;60(1):185-190.

77. Orlando MS, Likes KC, Mirza S, et al. A decade of excellent outcomes after surgical intervention in 538 patients with thoracic outlet syndrome. J Am Coll Surg. 2015;220(5):934-939.

78. Tender GC, Kline DG. Posterior subscapular approach to the brachial plexus. Neurosurgery. 2005;57(4):377-381.

79. Krähenbühl SM, Depairon M, Faure M, et al. Sildenafil as a therapeutic option for digital ischemic ulceration: case report. J Hand Surg Am. 2015;40(5):890-893. 